\title{
Ground heave movement evaluation in shallow foundations for expansive soils in Tunja, Colombia
}

\author{
Adriana Ochoa ${ }^{1, *}$, Carlos Sainea-Vargas ${ }^{1}$, and G.V. Ramana ${ }^{2}$ \\ ${ }^{1}$ Universidad Pedagógica y Tecnológica de Colombia, Civil Engineering School, Colombia \\ ${ }^{2}$ Indian Institute of Technology Delhi, New Delhi, India.
}

\begin{abstract}
A current challenge in unsaturated soil mechanics is the need to estimate ground heave and associated shallow foundation movements in expansive soils due to water content changes. Such estimation should be simple for geotechnical engineering practitioners and provide reliable foundation designs through quantifying the risk associated with the ground heave. The difficulties in generalizing a method are related to several variables influencing the expansive behavior, including the initial and final stress state condition, soil mineralogical composition, ground wetting depth, soil wetting degree, and geotechnical profile comprising soil strata thickness and groundwater condition. In this research, the evaluation of heave movements for the expansive soils located in the north-east of Tunja (Colombia) is performed through surrogate path (SPM), water content, and consolidation theory-based methods. Initial and final suction profiles were defined to quantify the wetting strains developed at each scenario of partial wetting. The sensitivity of the SPM to the estimated or measured value of constant volume swelling pressure was corroborated. The higher deformations that the soil profile would be able to develop when subjected to a progressive wetting were obtained along with the remaining heave capacity of the soil profile. Finally, concluding remarks and recommendations associated with the practicality and applicability of the methods are presented.
\end{abstract}

\section{Introduction}

Expansive soils are materials susceptible to volumetric changes due to variations in their water content. These materials have been considered natural hazards responsible for significant damage to structures of different complexity around the world [1]. The damage generated by these materials ranges from small fissures to large cracks due to heave that can lead to failure of both shallow and deep foundation elements and, therefore, affect a structure's functionality and safety.

Geotechnical engineers are challenged to find an effective and reliable method to evaluate the expansive potential of soils and develop designs within the allocated time and budget [2]. Usually, the optimal alternative of foundation design in this type of soil to minimize the risk of damages involves costs exceeding the initially anticipated for the project. That may explain why owners or investors decide to use a lower cost foundation system, regardless of the high risk the project could be subjected to[3][4].

The great difficulties in designing foundations for this type of soil profile are associated with the numerous factors that affect their behavior and the lack of practical and reliable methods that include most of them in their models. Among some of those factors that prevent the generalization of design methodologies, we can find: Type and quantity of expansive mineral, layer thickness, permeability, active zone, surcharge, dry density, climatic conditions, water content, and the stress state. These last two factors are especially important in the behavior experienced by a foundation supported on expansive soils. The ground movement is directly related to the response of the soil to changes in its stress state, which includes the effect generated by variations in water content [3]. The stress state of these materials is described by the variables named effective stress, net normal stress, and matric suction. The last two are considered the most important variables to study because they consider the air pore pressures generated within the material given the conditions or scenarios of partial saturation in which expansive soils are generally found, given their low permeability [3].

The adequate evaluation of the heave capacity of soils becomes a determining and imperative factor in assessing the risk due to heave in a foundation system [5]. Lessons to be learned about foundation design on expansive soils have come out of forensic investigations of projects that presented significant cracking, uplift, and failure of their foundation elements and/or the entire structure. These investigations identified a series of factors that contributed to the failure of the structures, among which we can find: deficiencies in subsoil exploration, sampling,

\footnotetext{
*Corresponding author: luz.ochoa@uptc.edu.co
} 
and geotechnical characterization both field and laboratory, the wrong definition of design variables such as the active zone, the estimation of heave and therefore an incorrect selection of the foundation system. Other factors are the lack of analysis of future groundwater conditions, inadequate drainage conditions, and poor construction practices ([6] [7] [8] [9]).

The present research was developed about the identification of the above factors and the need to study methodologies providing reliable information for the geotechnical design of structures over expansive soils. The focus is on studying methods for the adequate quantification of ground heave movements in partial saturation conditions. For the named purpose, and as a result of the review of the state of the art of the topic under study, the odometer-suction methods and the Surrogate Path Method (SPM) were selected. Those are practical and straightforward techniques that comprehensively include many of the previously mentioned factors influencing heave development and magnitude. Besides, the research is based on the need to characterize and explain the swelling capacity of the expansive materials present in Tunja. The city is located in the Eastern Ranges of the Colombian Andes- and more specifically in the geological formation named Tilatá that outcrops on the surface on the north-eastern flank of a synclinal. The location of the study site is presented in Fig. 1.
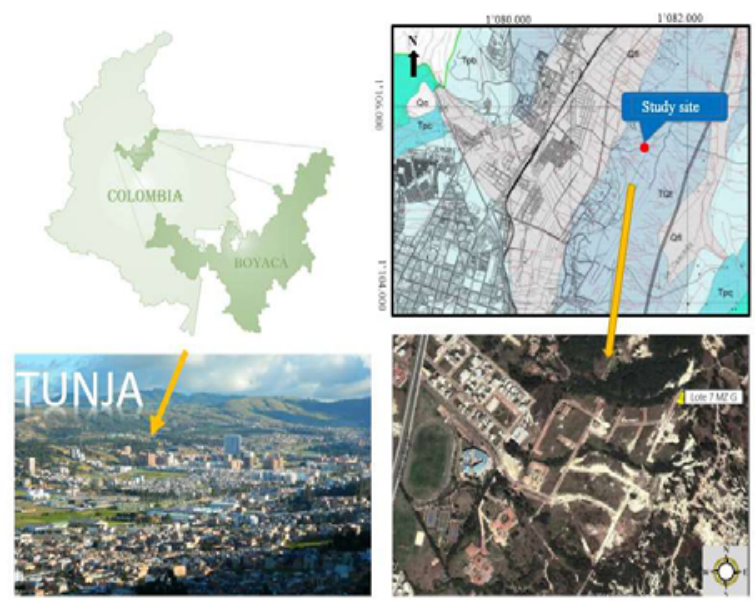

Fig. 1. Location of the study site.

\section{Surrogate Path Method (SPM)}

A method based on soil suction and the evaluation of the heave index, $\mathrm{C}_{\mathrm{H}}$, from constant volume swelling pressures, $\sigma^{\prime \prime}{ }_{c v}$ (measured or estimated), the swelling pressure, $\sigma^{\prime \prime}{ }_{c s}$, the inundation stress, $\sigma^{\prime \prime}{ }_{i}$, and percentage of swell, $\varepsilon_{s(\%)}$. Obtained from Consolidation-Swell tests. The method performs interpolation from the volume change-suction net stress space to the net stress plane. It accounts for partial wetting conditions and corresponding swelling pressures, identified as point $F$ in Fig. 2. Where the surrogate path is identified by the path GQB that saves a proportion to the alignment IFB. In which a decrease in matric suction values occurs when an increase in water contents presents. The ratio in which the suction is dissipated is analyzed in the method as a proportionality factor $R w$ from which it is possible to estimate the final net stress, $\sigma^{\prime \prime}{ }_{P}$, at point $P$. This point represents the net stress path, the final swelling pressure developed by the sample for the evaluated partial wetting conditions. At that point, a strain equal to $P Q$ is produced and describes the final percent of swell at the point $P$ of interest [10].

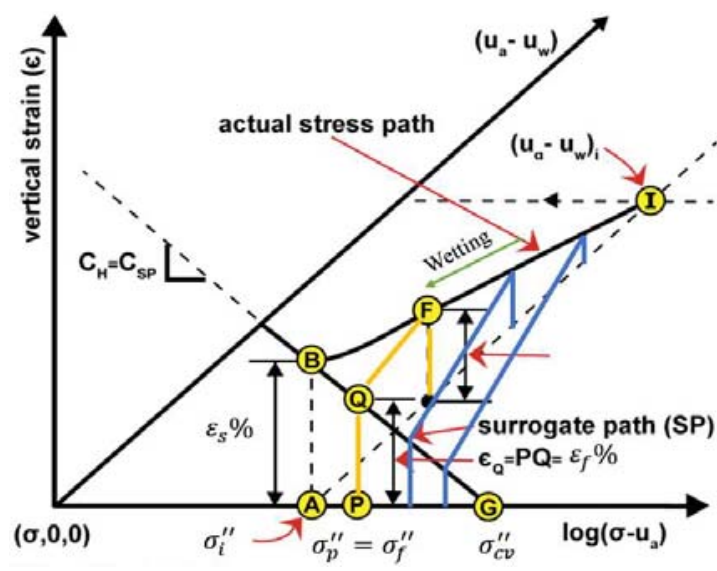

Fig. 2. Surrogate Path Method. Modified of [10].

The SPM requires to measure or estimate the initial suction $\left(\mu_{a}-\mu_{w}\right)_{i}$, and final suction conditions $\left(\mu_{a}-\right.$ $\left.\mu_{w}\right)_{f}$ of the soil profile. Information that is used to calculate the proportionality factor $R w$ at the different wetting conditions. The factor, then is defined as:

$$
R_{W}=\frac{\left(\mu_{a}-\mu_{w}\right)_{f}}{\left(\mu_{a}-\mu_{w}\right)_{i}}
$$

$R w=1$ for no wetting as if $R w=0$ full wetting has occurred. The wetting degree can be estimated as $1-R w$. The suction profiles defined previously are dependent and must be determined taking into account the boundary conditions that persist on the study site at the project construction time and even years after.

The final net stress for partial wetting conditions, $\sigma^{\prime \prime}{ }_{F}$ or $\sigma_{P}^{\prime \prime}$ can be calculated as:

$$
{\sigma^{\prime \prime}}_{P}=\sigma^{\prime \prime}{ }_{i}+R_{W}\left(\sigma^{\prime \prime}{ }_{C V}-\sigma^{\prime \prime}{ }_{i}\right)
$$

\section{Experimental work and results}

The research was conducted in 6 steps that will be explained in detail below, along with the obtained results.

\subsection{Data acquisition and analysis}

The physical and heave capacity characterization was obtained and synthesized from 300 boreholes conducted to varying depths of $3,6,8,12$ and $15 \mathrm{~m}$ by a consulting company of the region. An average of 1500 betweeen disturbed and undisturbed samples were obtained. From 
the soil reports, physical properties such as water content, Atterberg limits, unit weight, and the fraction finer than sieve $\mathrm{N}^{\circ} 200$ were obtained. Percent swell, $\varepsilon_{s \%}$, and the swelling pressure evaluated from consolidation-swell tests (CS) as well as swelling pressure from constant volume test $(\mathrm{CV})$ were available and characterized for the soil profile type defined for the study area. Additional tests such as hydrometer, volume-mass relationships, and specific gravity were conducted.

The present research profile type corresponds to a natural soil profile of fine-grained clayey materials with high plasticity appearing from the surface at $1.0 \mathrm{~m}-$ or 2.0 $\mathrm{m}$, in some areas- and extending to the explored depth of $15 \mathrm{~m}$, at which no water level was found. It is presumed by hydrogeology and near deep wells data that the water level at the study site can be found at around $30 \mathrm{~m}$ depth. From the water content profile, the active zone of the study site was defined and established at $9.0 \mathrm{~m}$. Depth from which no significant variation of water content occurs and therefore no significant swelling is possible to develop.

In Fig. 3, the index properties and soil classification varying with depth are presented; it should be noticed that the maximum liquid limit and plasticity index values are found from 3.5 to $8.0 \mathrm{~m}$, between $81 \%$ and $45 \%$, respectively.

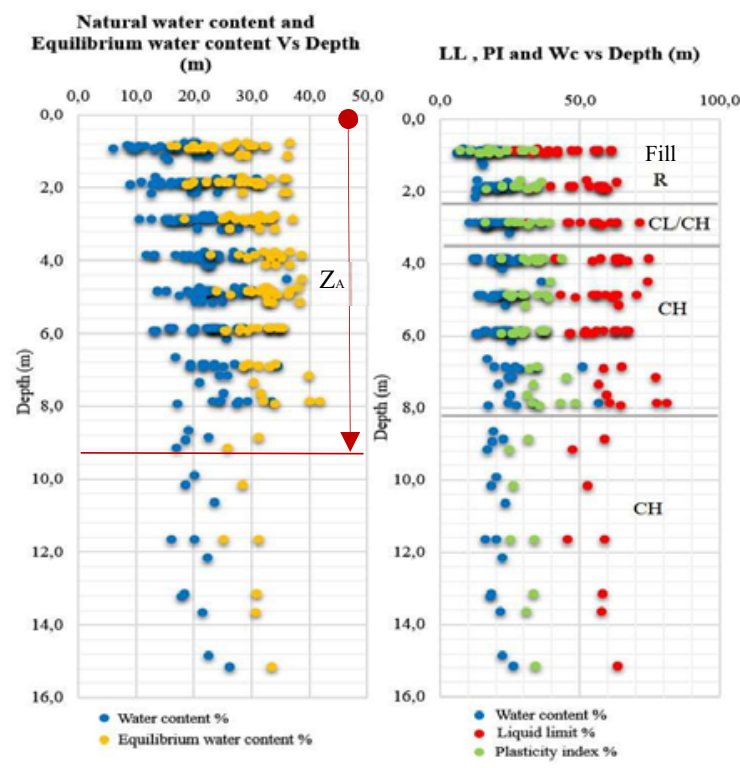

Fig. 3. Index properties vs. depth.

According to USCS, the soil profile is characterized as a high plasticity clay $(\mathrm{CH})$ with mainly medium to high swelling potential. The expansive potential was characterized to vary from medium to very high taking into account several correlations that relate the activity and index properties of the material such as the plasticity index, liquid limit and the percentage of clay. It is important to mention that the behavior of the material in the study site is dominated by clay particles, found in an $82 \%$ at the top with $17 \%$ silt, and diminishes to nearly
$60 \%$ at a depth of $8.0 \mathrm{~m}$, at which the sand content increase to a $6 \%$ and the silt fraction corresponds to nearly $34 \%$.

\subsection{Microstructure properties}

The microstructure of the materials at the study site was characterized with the aid of several tests performed on undisturbed samples of varying depths, such as: $2.0 \mathrm{~m}, 4.0$ $\mathrm{m}, 5.0 \mathrm{~m}, 6.0 \mathrm{~m}$ and $8.00 \mathrm{~m}$. Samples prepared according to the tests standards. Among them, X-ray diffraction (XRD), Scanning Electron Microscopy (SEM), Transmission Electron Microscopy (TEM), and Energy Dispersive X-Ray Analysis (EDX). Results and characterization obtained are described below in terms of particle size distribution, mineralogical composition, and micro-morphology.

From the images taken at 25,000 X through the SEM technique, the clay factory, due to the orientation of the soil particles, is described as flocculated and aggregated, see Fig. 4.

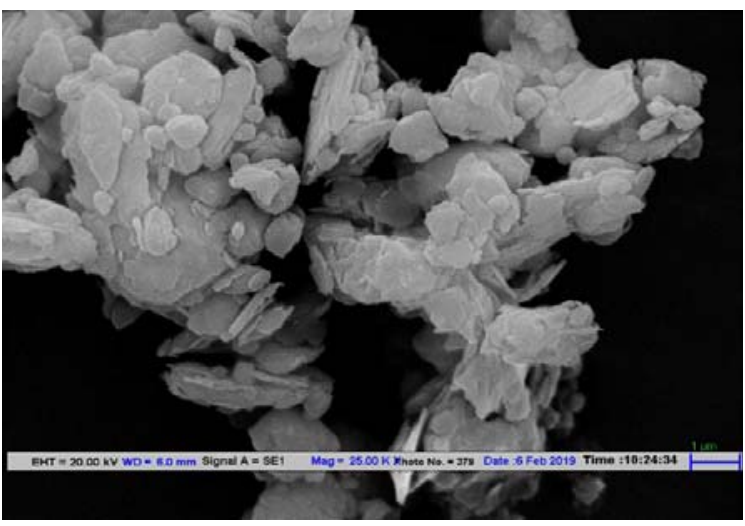

Fig. 4. Microstructure obtained from SEM- techniques compared to modes of particle association.

This type of structure is characterized by face-to-face (C-C) and an edge to face (B-C) particle association. The stacking of several layers gives the aggregation description of the fabric. Still, such aggregations in some particles are shown to be dissociated or non-flocculated and do not form a completely connected network [11]. The structure is characteristic of a kaolinite mineral whose chemical composition is characterized by strong bonds between particles. However, the non-flocculation found in the studied samples in some of their associations generates large areas where the bonds are weak, water can easily enter and get into contact with them, and some dispersion is possible to develop [11]. This feature of the soil at the study site would be related to the development of a more effective crystalline and osmotic expansion in the soil particles that could explain the expansive capacity of the soil profile, since the weak bonds reduce the interparticle forces that oppose the expansion.

In terms of the mineral composition the soil profile presents a important presence of Muscovite (9-11\%), with 
Kaolinite and Quartz dominating the soil structure in 53 and $40 \%$, respectively. Crystalline phases of Anorthite, Talc, Microcline, Anatase, and tremolite were encountered at a proportion inferior to $2.5 \%$ in the XRD analyzed samples. This characterization was compared to the one provided by index properties correlations, and no relation was found, since this last method associated the expansive potential to mainly Illite and Montmorillonite. Further studies needs to be develop to analyze the influence of structure types in the Kaolinites expansive behavior.

\subsection{Expansive behavior}

The swelling pressure profile and percent of swelling were defined for the typical soil profile with the results of consolidation-swell tests (CS) and constant volume (CV) tests. The resultant profile compared to the vertical net normal stress $\left(\sigma_{v o}^{\prime \prime}\right)$ at each layer is presented in Fig. 5. An increasing trend of swelling pressures shows up to a depth of $6.5 \mathrm{~m}$, where the maximum value measured in the laboratory is reached and corresponds to $745 \mathrm{kPa}$, for free swell conditions. In terms of $\mathrm{CV}$, the maximum value is reached between 6.5 and $9.0 \mathrm{~m}$, quantified in $360 \mathrm{kPa}$. From here, the maximum depth with expansion potential was confirmed to be found at $9 \mathrm{~m}$ - as the water content variation profile previously described -, since the overload exceeds the swelling pressures developed by the soil when changes in water content occur. From this point forward, no expansion would develop (See Fig. 5).

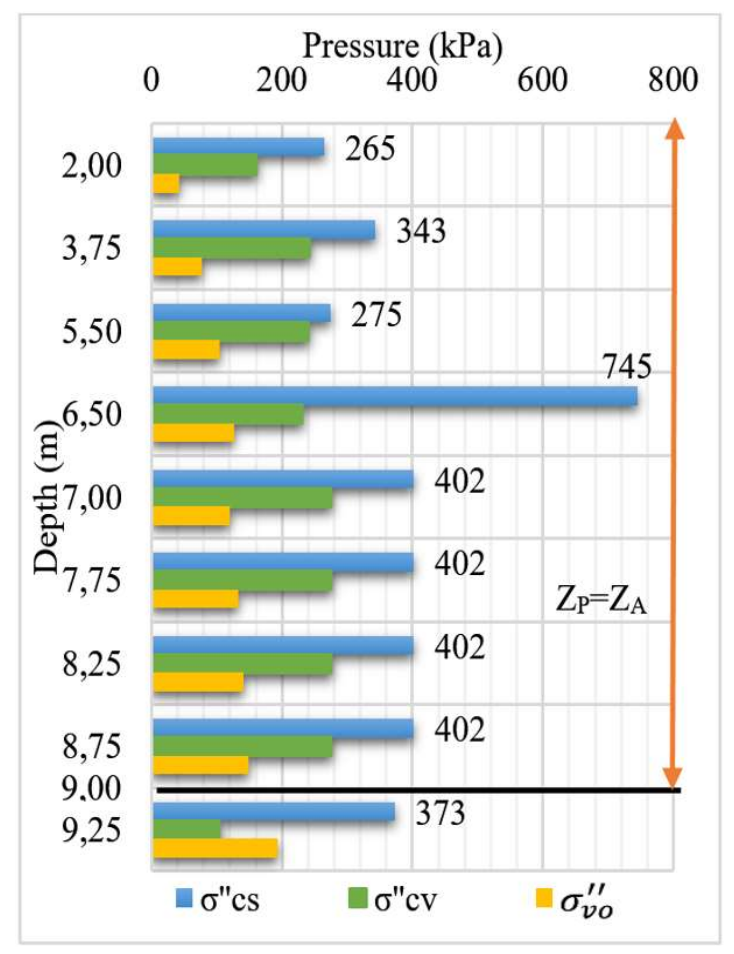

Fig. 5. Swelling pressures and net total stress relations vs depth.

The heave index, $\mathrm{C}_{\mathrm{H}}$, (required to implement the Surrogate Path Method) is a variable that describes the expansion potential of materials. The higher, the greater the deformations that the soil profile can develop. The index was calculated for each of the strata from the equation (3) that relates the free percent swell, $\varepsilon_{s \%}$, constant-volume swelling pressure, $\sigma^{\prime \prime}{ }_{c v}$ - the calculation of the heave index and partial swelling pressures were both made from values measured in the laboratory and estimated values of this variable -, and the inundation stress, $\sigma^{\prime \prime}{ }_{i}$, The results are summarized in Table 1.

$$
C_{H}=\frac{\varepsilon_{S \%}}{\log \frac{\sigma_{c v}^{\prime}}{\sigma_{i}^{\prime}}}
$$

In general, in the study area, the heave index acquires high values and finds its maximum values in the soil strata from 5.5 to $6.5 \mathrm{~m}$ and 8.5 to $9 \mathrm{~m}$. The results are coherent with the high expansive potential identified previously by index properties. Also, they indicate the capacity of the soil profile to develop large ground heave movements that could affect the functionality and safety of the structure if changes in the water content of the soil profile occur.

Table 1. Expansion Index.

\begin{tabular}{|l|c|c|c|}
\hline Strata & Depth (m) & $\mathbf{\varepsilon s} \mathbf{( \% )}$ & $\mathbf{C}_{\mathbf{H}}$ \\
\hline Filling & $0.0-1.0$ & 0,2 & - \\
\hline $\mathrm{CL} / \mathrm{CH}$ & $1.0-3.0$ & 2,9 & 4,9 \\
\hline \multirow{2}{*}{$\mathrm{CH}$} & $3.0-4.5$ & 5,2 & 10,4 \\
\hline \multirow{2}{*}{$\mathrm{CH}$} & $4,5-5.5$ & 5,9 & 16,4 \\
\hline \multirow{4}{*}{$\mathrm{CH}$} & $5,5-6.5$ & 7,6 & 28,7 \\
\hline & $6,5-7.5$ & & 20,3 \\
\cline { 2 - 2 } & $7,5-8.0$ & \multirow{2}{*}{6,1} & 23,8 \\
\cline { 2 - 2 } & $8.0-8.5$ & & 26,6 \\
\cline { 2 - 2 } & $8,5-9.0$ & & 29,9 \\
\hline \multirow{2}{*}{$\mathrm{CH}$} & $9,0-9.5$ & 5,0 & 0,0 \\
\hline
\end{tabular}

\subsection{Suction measurements Filter Paper Method}

The measurement of matric and total suction was performed following the procedure described by ASTM D5298-10 [12] to measure soil potential using filter paper. A test whose procedure began with the drying in the oven for a minimum of 16 hours of the filter paper of reference Whatman $\mathrm{N}^{\circ} 42$ to be used, followed by the preparation of the samples and containers. The dried filter papers were stored in vacuum-sealed containers until their use in the test. For this research, both total suction (sample and filter paper not in contact) and matric suction (filter paper and soil sample in contact) were measured. The samples were placed inside glass containers and stored for 10 days in a polystyrene refrigerator to isolate them and minimize temperature variation accordingly to the standard. The setup of the test is presented in Fig. 6. Relative humidity and temperature checkups were performed with a digital thermo-hygrometer to minimize condensation effects. The suction of the filter paper was obtained from the calibration curve of the standard.

From the calibration curve of the filter paper and the water content of the soil samples, the obtained values of total and matric suction are summarized in Table 2. 
Table 2. Results of total and matric suction.

\begin{tabular}{ccccc}
\hline & $\begin{array}{c}\text { Total } \\
\text { Suction } \\
\text { (Average) }\end{array}$ & $\begin{array}{c}\text { Matric } \\
\text { Suction } \\
\text { (Average) }\end{array}$ & $\begin{array}{c}\text { Soil } \\
\text { Water } \\
\text { Content }\end{array}$ & $\begin{array}{c}\text { Degree } \\
\text { of Sat. }\end{array}$ \\
\hline Test & $\mathbf{( k P a )}$ & $\begin{array}{c}\text { Ua-Uw } \\
\text { (kPa) }\end{array}$ & $\mathbf{C a \%}$ & $\mathbf{S}$ \\
\hline FP 1 & 1290 & 1176 & 18,7 & 0,60 \\
\hline FP 2 & 4416 & 1979 & 16,2 & 0,52 \\
\hline
\end{tabular}

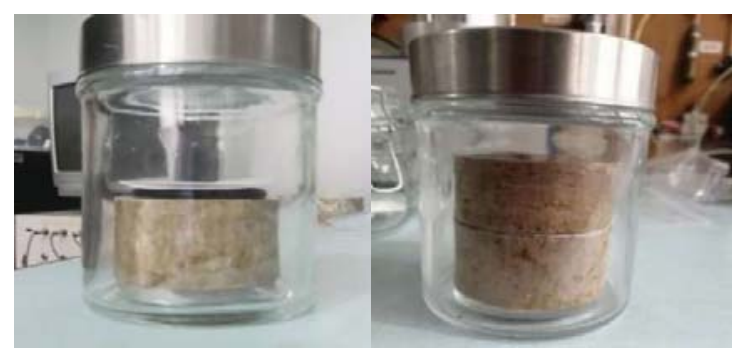

Fig. 6. Filter Paper Method tests setup.

\subsection{Soil Water Characteristic Curve (SWCC)}

The method of Fredlund and Xing[13] with the fitting parameters models of Chin et al. [14] and Zapata [15] was used to obtain the SWCC of the expansive soils in the north-eastern sector of Tunja (Colombia) from the limited experimental data of matric suction obtained through the Filter Paper tests, the evaluation of the degree of saturation of the material and the index properties. A brief description of the process and results that led to the definition of the SWCC for the soil profile is provided below.

The first method applied correspond to Fredlund and Xing[13] with the model of Chin et al. [14], which equations are presented in Table 3. The model uses a trial and error process to obtain the $\mathrm{X}$ parameter present in all equations to define the SWCC where the measure limited data (FP1 and FP2) fits or passes through. In that process several curves were generated on a semi-logarithmic scale and the one that showed the greatest agreement with the laboratory data was selected and is presented in Fig. 7. To which, the values of the fitting parameters of the SWCC corresponds to $X=221, m=0.66, n=0.61$, and $a=191.6$. The magnitude of this last parameter is an important indicative that the curve obtained corresponds to one developed in the desorption trajectory. Under those conditions, the saturation values of the soil profile planned to study would have associated the higher suction values [16]. Therefore, from this SWCC the higher ground movements and the maximum strains of the soil profile in study due to heave could be estimated.

The curve obtained was compared to those studied in the limited data model of Ren et al.[17] that uses the Van Genuchten model and data compiled from 78 characteristic curves of different types of materials. The reference with which the experimentally measured suction data were most closely matched was Vanapalli et al.[18]. Whose characteristic curve was obtained by laboratory suction measurements without applying any confining pressure for the red silty clay of Guadalix. The curve is also shown in Fig. 7 along with its characteristic points $\mathrm{C}_{1}, \mathrm{~S}$, and $\mathrm{C}_{2}$, which corresponds to the air-entry value, inflection point, and the residual suction zone of the curve, respectively.

Table 3. Equations to obtain SWCC.

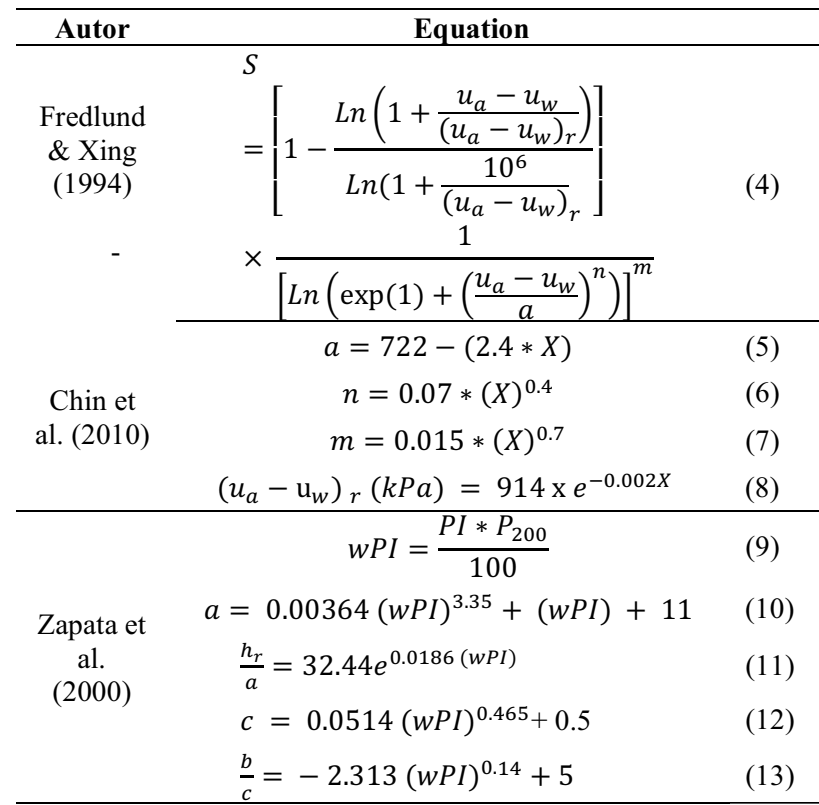

Where:

$u_{a}-u_{w}$, matric suction

$\left(u_{a}-u_{w}\right)_{r}$, matric suction of reference

$w P I$ is the plasticity index (\%), and $P 200$ is the percent of soil passing sieve $\mathrm{N}^{\circ} 200(\%) ; a, b, c, h r=$ Fitting parameters

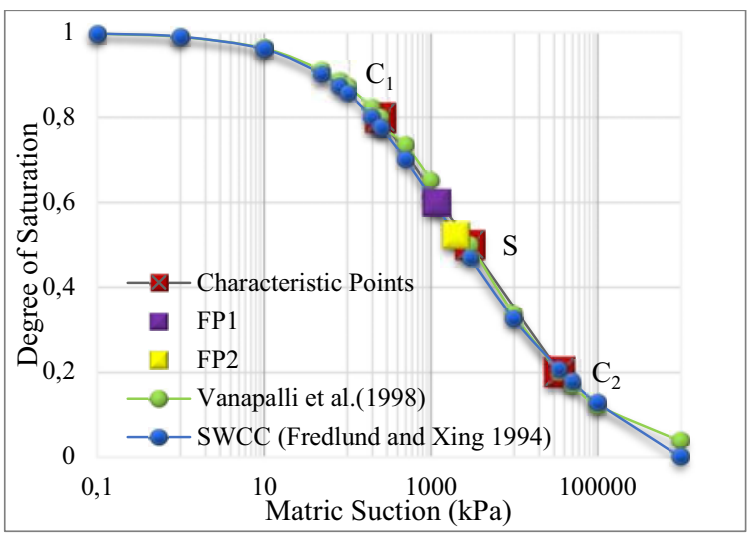

Fig. 7. SWCC with characteristic points.

In addition, the curves were compared to the family of SWCC obtained from the Zapata model based on index properties [15] (See Table 3), which show a displacement and location towards the right side of the curve (See Fig. 8) with $w P I$ values between 40 and 50, associated equally to the highest suction levels.

The curves obtained by the different methods showed a high correlation and fit between the estimated curves, 
which reduces the uncertainty in their definition generated by the limited experimental data. The curve developed by the method of Fredlund and Xing [13] and the model of Chin et al[14] was selected as the characteristic curve of the material, since it easily allows the estimation of suctions for the scenarios and partial saturation profiles that were planned to be studied.

Point $\mathrm{C}_{2}$ of the SWCC calculated in $39811 \mathrm{kPa}$ was selected as starting point for the progressive scenarios of wetting and estimation of the corresponding ground heave movements.

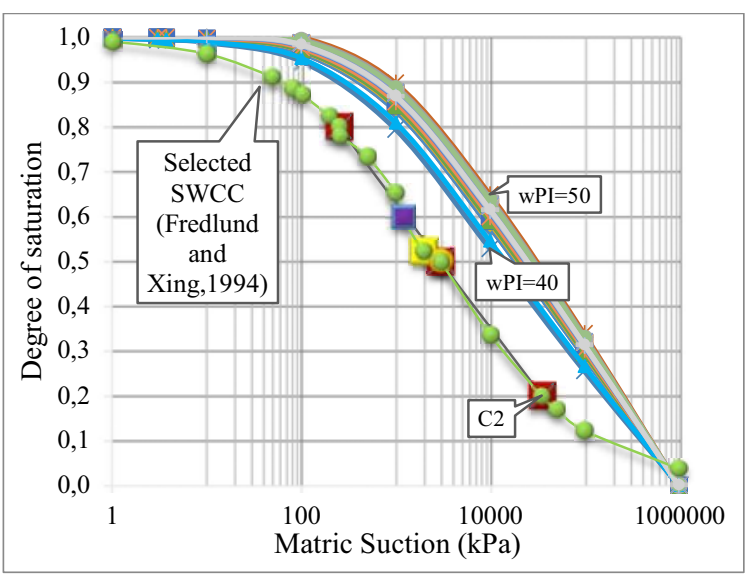

Fig. 8. SWCC from wPI and selected SWCC.

\subsection{Ground heave movement evaluation}

For this matter, the process was conducted following the steps described in the Surrogate Path Method [10], summarize in:

(a) Definition of the initial suction profile and boundary conditions of the model. For the research, BC1 was selected as the boundary conditions of the model. According to it, the project construction could occur when the suction profile is at any point between the driest and wettest conditions, and the suction profile swings cyclically from a driest to wettest state.

(b) Definition of the final suction profile for each wetting scenario. Six scenarios of progressive wetting varying from the suction value of $\mathrm{C}_{2}$ to minimum values between 3 to $34 \mathrm{kPa}$ at the wettest scenario.

Fig. 9 shows the corresponding suction values for each initial and final wetting condition evaluated in the scenarios. Meanwhile, Fig. 10 presents the soil saturation profiles at the end of each wetting process. The average percentage increase of the degree of saturation at each scenario for the soil profile correspond to: $\mathrm{A}_{(\mathrm{C} 2 \text { to } \mathrm{Ca} 1)}=25 \%, \mathrm{~B}\left(\mathrm{Ca}\right.$ to $\left.\mathrm{Ca}_{2}\right)=26 \%, \mathrm{C}$ ${ }_{(\mathrm{Ca} 2 \text { to } \mathrm{Ca} 3)}=18 \%, \mathrm{D}_{(\mathrm{Ca} 3 \text { to } \mathrm{Ca} 4)}=6.9 \% ; \mathrm{E}_{(\mathrm{Ca} 4 \text { to } \mathrm{Ca} 5)}=7.2 \%, \mathrm{~F}$ $(\mathrm{Ca} 5$ to $\mathrm{Ca} 6)=12.3 \%$. Values defined by the author given is experience, data of historic water content profiles of the studied area and research objectives. (c) Division of the soil profile into sublayers to the maximum depth of wetting. See Table 1.

(d) Evaluation of partial wetting strain using the SPM.

(e) Compute the heave contribution of each sublayer to obtain the ground movement due to heave at each scenario. Results are presented in Fig. 11.

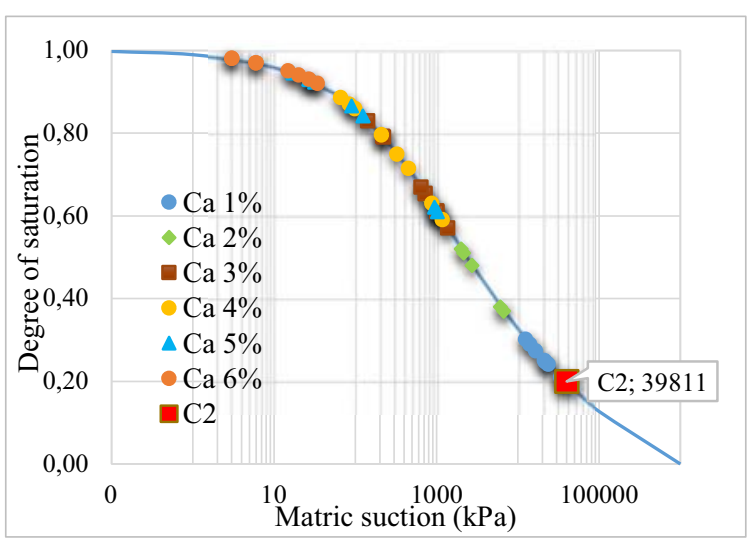

Fig. 9. Range of suction values studied with the partial wetting scenarios.

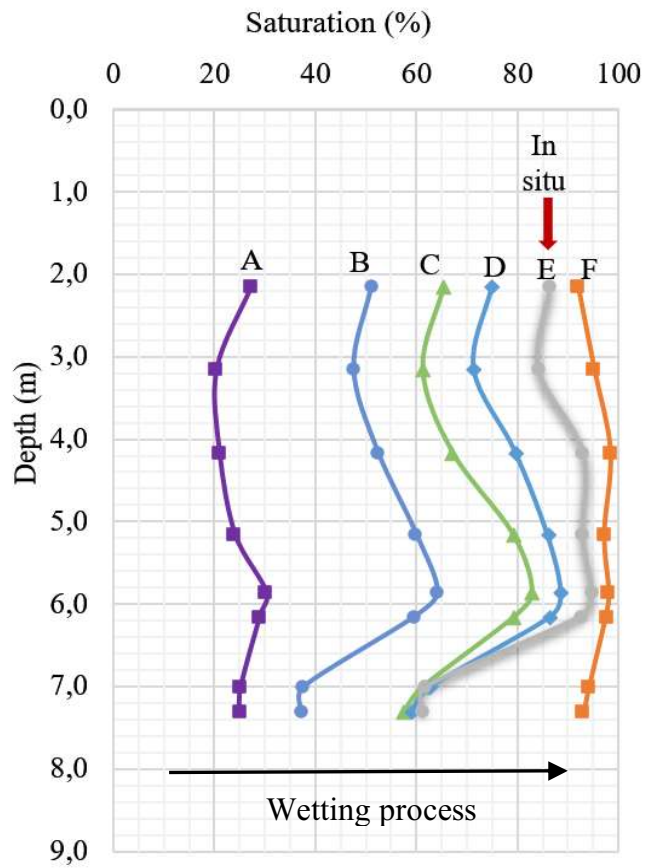

Fig. 10. Saturation profiles for wetting scenarios from $A$ to $F$.

In agreement with the procedure described, the corresponding net stress for partial wetting conditions, $\sigma_{P}^{\prime \prime}$ and strains $(\rho)$ of the soil profile type in the six scenarios were obtained using the proportionality factor, $R_{w}$, index heave, $C_{H}$, and the corresponding variables of the SPM. Computation of the heave contribution of each sublayer based on its thickness was performed, and the total heave ground movement of each scenario was calculated. The cumulative heave from the driest $\left(\mathrm{C}_{2}\right)$ to the full wetted state was quantified in $118 \mathrm{~cm}$. Results are present graphically in Fig. 11 and Fig. 12. The results 
obtained should be read taking into account the following observations:

- The soil profile in scenarios A and D develops the highest expansion pressures due to the high suction dissipation generated by wetting, as can be seen in Fig. 12. Therefore, the higher ground movements due to heave, quantified in 39 to $43 \mathrm{~cm}$ and 26 to 24 $\mathrm{cm}$, respectively.

- In scenarios $\mathrm{B}$ and $\mathrm{F}$, the lowest pressures are developed consistent with the values of the $R_{w}$ factors obtained close to 0 .

- Scenarios C and E represent a condition of intermediate pressures in which there is no significant difference in the magnification of the developed swelling pressures.

- No significant difference in the quantification of ground movement due to heave was found in the scenarios, since the SPM results are not very sensitive to the variation in the value of the constant volume swelling pressure when estimated from the free swelling tests, as Fig. 12 also shows.

- The initial water content profile of scenario F, corresponds to the in-situ conditions found at the study site. Therefore, the remained swelling capacity of the soil is studied in this scenario and estimated to be $9 \mathrm{~cm}$.

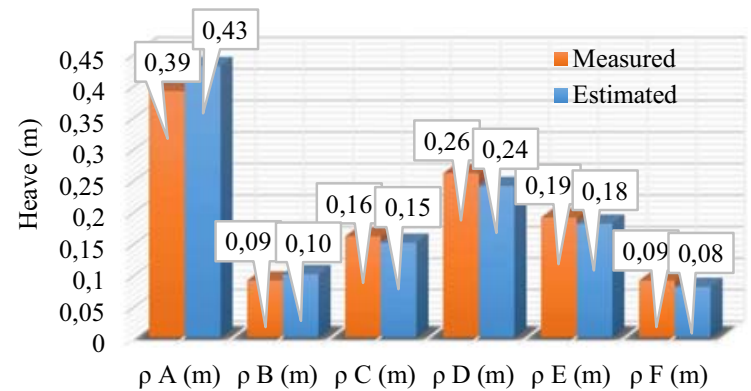

Fig. 11. Ground heave movement at each scenario.

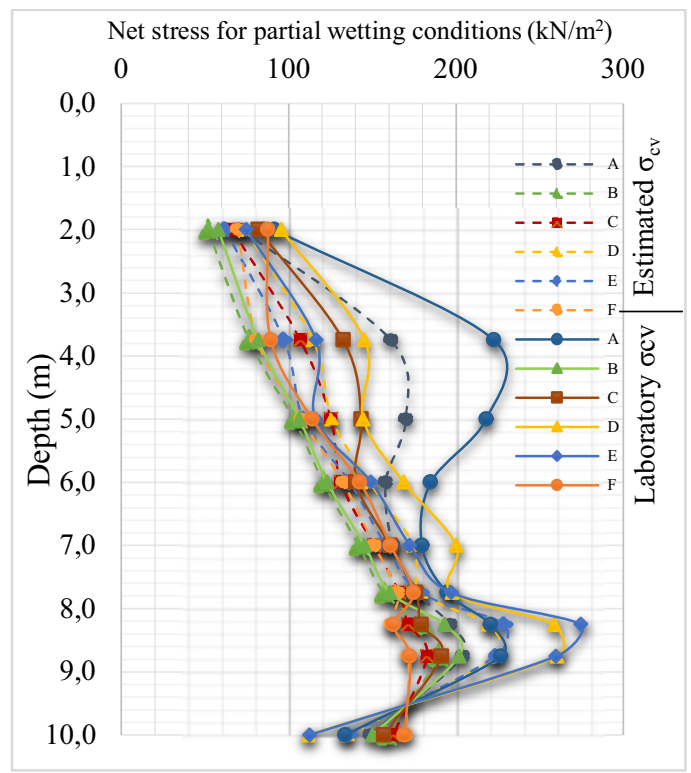

Fig. 12. Swelling pressure for partial wetting conditions.
The results obtained in terms of the total ground movement and remained heave capacity that the soil profile could potentially develop if changes in its water content occur, are consistent with the thickness of expansive soil, the magnitude of the pressures, and the percentages of both total and partial expansion obtained in each scenario. Similar magnitudes to those obtained in the present research were obtained by Overton et al, 2006 [19], where several two-dimensional seepage analyses were developed to evaluate the migration of the wetting front, effects of poor drainage in heave development, and to predict values of potential heave versus the lifetime of a structure for different configurations of a soil profile. The research was conducted for sites with low, moderate and highly expansive soils, and some heave magnitudes were quantified in $120.1 \mathrm{~cm}, 131.1, \mathrm{~cm}$ and $140.5 \mathrm{~cm}$ for three configurations of the soil profile and depths of potential heave.

\section{Conclusions and remarks}

It was found that the soil at the study site has a capacity to heave $118 \mathrm{~cm}$, if a full wetting occurs from its residual suction zone. The established boundary conditions define that the expansions evaluated correspond to the most critical and, therefore, will be the maximum deformations associated with this phenomenon that the soil profile would be able to develop when the conditions resemble to one of the scenarios here studied.

If the in-situ conditions are preserved and considered as design variables, the maximum deformation due to heave if wetting occurs in the study area will correspond to $9 \mathrm{~cm}$, as evaluated in scenario $\mathrm{F}$.

The quantified ground heave movement is representative of a soil profile subjected to a progressive wetting process whose active zone goes up to $9.0 \mathrm{~m}$.

A good agreement was found between the results of net stresses for partial wetting conditions based on measured laboratory data of constant swelling pressure and those estimated through equation. Therefore, to some extent it is corroborated that the results of the SPM method as described by its author are not very sensitive to the estimate of the constant volume swelling pressure. Then, the method can be applied if data from free swelling tests is available.

Given the above, the author concludes that the Surrogate Path Method is a tool of simple application that should be implemented more frequently in professional practice, since is founded on the full wetting oedometer test. Its practicality to assess volume changes for different conditions of partial saturation on a soil profile such as those developed along the different stages of the construction process of a project makes it suitable for the geotechnical engineering practice. 


\section{Acknowledgments}

The first author gratefully acknowledges the Indian Institute of Technology Delhi's support for the microstructure tests and the test data of soil reports provided by the consulting company López Hermanos S.A.S.

\section{References}

1. A.A Al-Rawas, \& M.F. Goosen. (2006). Expansive Soils Recent Advances in Characterizarion and treatment. London: Taylor \& Francis Group.

2. H. Elbadry. (2015). Simplified reliable prediction method for determining the volume change of expansive soils based on simply physical tests. HBRC Journal, 353-360.

3. J.D Nelson, K.C. Chao,D.D Overton, \& E.J Nelson. (2015). Foundation engineering for expansive soils. New York: John Wiley \& Sons, Inc.

4. W. Mingwu,\& C. Guanyi. (2011). A novel coupling model for risk analysis of swell and shrinkage of expansive soils. Computers and Mathematics with Applications, 2854-2861.

5. J. D.Nelson, K.C. Chao, D.D. Overton, \& J. Dunham-Friel. (2011). Evaluation of level of risk for structural movement using expansion potential. Geo-Frontiers, 2404-2413.

6. Wayne, Osman, \& Ali. (1984). Construction on Expansive Soils in Sudan. Journal of Construction and Management, 359-374.

7. S. Houston, H. Dye,C. Zapata, K. Walsh, \& W. Houston. (2011). Study of Expansive Soils and Residential Foundations on Expansive Soils in Arizona. Journal of Performance of Constructed Facilities, 31-44.

8. M. Ozer, R. Ulusay, \& N. Isik.(2011). Evaluation of damage due to light structures erected on a fill material rich in expansive soil. Bull Eng Geol Environ, 21-36.

9. E.J. Nelson, K.C. Chao, J.D. Nelson, \& D.D. Overton. (2016). Lessons Learned from Foundation and Slab Failures on Expansive Soils. Journal of Performance of Constructed Facilities, D4016007-1 a DP4016007-14.

10. S.L. Houston, \& W.N. Houston. (2017). Suction-Oedometer Method for Computation of Heave and Remaining Heave. PanAm Unsaturated Soils 2017 : Plenary Papers. GSP 300 . 2018.

11. E. S. Velasco. (2013). Scanning Electron Microscope (SEM) images as a means to determine dispersibility. Ames, Iowa. IOWA STATE UNIVERSITY Digital Repository. Graduate Theses and Dissertations. 13396.

12. ASTM International. (2016). ASTM D529816. Standard Test Method for Measurement of Soil Potential (Suction) Using Filter Paper. West Conshohocken. doi:10.1520/D5298-16.

13. D. Fredlund, \& A. Xing. (1994). Estimation of The Soil-Water Characteristic Curve of Coarse-Grained Soils Using One Point Measurement and Simple Properties. Can. Geotech. J., 31, 521-532.

14. K.B. Chin, E.C. Leong, \& H. Rahardjo (2010). "A Simplified Method to Estimate The Soil-Water Characteristic Curve. Can. Geotech. J., 47(12), 1382-1400.

15. C. E. Zapata, , W. N. Houston, S. Houston, \& K. Walsh. (2000). Soil-Water Characteristic Curve Variability. Advances in Unsaturated Geotechnics. ASCE - GEO Institute Geotechnical Special Publication, 84-124.

16. D. Fredlund, H. Rahardjo, \& M. Fredlund. (2012). Unsaturated Soil Mechanics in Engineering Practice. New Jersey: John Wiley \& Sons.

17. X. Ren, J. Kang, J.Ren, X. Chen, \& M. Zhang. (2020). A method for estimating soil water characteristic curve with limited experimental data. Geoderma, 1-14.

18. S. Vanapalli, \& L. Lu. (2012). A state-ofthe art review of $1-\mathrm{D}$ heave. International Journal of Geotechnical Engineering, 15-41.

19. D. Overton, K. Chao, \& J. Nelson. (2006). Time Rate of Heave Prediction for Expansive Soils. GeoCongres2006: Geotechnical Engineering in the Information Technology Age. ASCE. 